\title{
SOLAR CYCLE VARIATION OF COSMIC RAY INTENSITY ALONG WITH INTERPLANETARY AND SOLAR WIND PLASMA PARAMETERS
}

\author{
Rajesh K. Mishra ${ }^{1}$, Rekha Agarwal ${ }^{2}$ and Sharad Tiwari ${ }^{1}$ \\ ${ }^{1}$ Computer and Information Technology Section, \\ Tropical Forest Research Institute, \\ P.O.: RFRC, Mandla Road, Jabalpur (M.P.) 482 021, INDIA \\ 2 Department of Physics, Govt. Model Science College (Autonomous), \\ Jabalpur (M.P.) 482 001, INDIA
}

\begin{abstract}
Galactic cosmic rays are modulated at their propagation in the heliosphere by the effect of the large-scale structure of the interplanetary medium. A comparison of the variations in the cosmic ray intensity data obtained by neutron monitoring stations with those in geomagnetic disturbance, solar wind velocity (V), interplanetary magnetic field (B), and their product $(\mathrm{V} \times \mathrm{B})$ near the Earth for the period 1964-2004 has been presented so as to establish a possible correlation between them. We used the hourly averaged cosmic ray counts observed with the neutron monitor in Moscow. It is noteworthy that a significant negative correlation has been observed between the interplanetary magnetic field, product $(\mathrm{V} \times \mathrm{B})$ and cosmic ray intensity during the solar cycles 21 and 22 . The solar wind velocity has a good positive correlation with cosmic ray intensity during solar cycle 21 , whereas it shows a weak correlation during cycles 20,22 and 23 . The interplanetary magnetic field shows a weak negative correlation with cosmic rays for solar cycle 20 , and a good anti-correlation for solar cycles 21-23 with the cosmic ray intensity, which, in turn, shows a good positive correlation with disturbance time index $\left(\mathrm{D}_{\mathrm{st}}\right)$ during solar cycles 21 and 22 , and a weak correlation for cycles 20 and 23. number.

Key words: cosmic rays, solar cycle, interplanetary magnetic field, sunspot
\end{abstract}

\section{INTRODUCTION}

The study of the long- and short-term modulation of galactic cosmic rays above $\sim 3 \mathrm{GV}$ has relied for many decades upon the world-wide network of neutron monitors (NMs), which measure the nucleonic cascades in the Earth's atmosphere and provide the only long-term measurements of the high-energy cosmic rays.

Ground-based NMs at several locations on the Earth for the last several decades have regularly been monitoring the cosmic rays. The observations so far have clearly indicated a solar cycle effect, with the largest reductions in the cosmic ray intensity during the sunspot maximum years $[1,2]$.

The intensity of galactic cosmic rays measured on Earth is related to the Sun's cycle of activity, which is well known. The solar magnetic field flips every 11 years, and the number of sunspots and the so-called coronal mass ejections rises and falls twice in each complete 22-year cycle. The cosmic ray intensity on the Earth also peaks twice every 22 years in time with the solar cycle. Cliver and Ling 
[3] have discovered a quirk in this pattern - they believe that it is caused by coronal mass ejections.

The intensity of cosmic rays varies at different time scales, from minutes to decades and even beyond. These variations can be studied using the data from ground-based neutron monitors. Berezhko et al. [4] found a significant solar cycle variation in the cosmic ray fluctuation magnitude for 1980-1990 using 5-min. data from the Tixie Bay NM. A solar cycle change was also found in the spectrum of small-scale turbulence [5]. The solar cycle variation in cosmic ray fluctuations was verified for two solar cycles (1980-2002) using the data from two remote polar neutron monitors, Oulu and Tixie Bay [6].

The study of modulation of galactic cosmic rays is important because of its potential for revealing subtle features of the energetic charged particle transport in the tangled fields that permeate the heliosphere, and in part as a means of remotely probing the heliosphere, as well as for learning about the physics of the processes going on the Sun.

The 11-year galactic cosmic ray modulation has been studied quite vigorously since the work of Forbush [1]. He discovered an anti-correlation between the cosmic ray intensity and the sunspot numbers. We know now that sunspots are the sites of intense magnetic fields on the Sun's photosphere. Moreover, a case has been made that the local value of the interplanetary magnetic field (IMF) plays a significant role in controlling cosmic ray modulation at a site of observation [7-10].

The long-term cosmic-ray (CR) modulation cycle has a well known 11 -year variation with solar cycle, and a 22-year cycle coinciding with the polarity cycle of the solar magnetic field. The cosmic ray time profiles are more flat-topped (sharply peaked) around the solar minimum when the IMFs have a positive (negative) polarity in the northern hemisphere. This phenomenon is likely due to CR gradient, curvature, and current sheet drift transport, which depends on the sign of the magnetic field polarity $[11,12]$. In the beginning of a positive polarity cycle, the cosmic-ray intensity can increase quickly over a $1-2$ year time, so that relatively early in the cycle the $\mathrm{CR}$ intensity and the associated radiation hazard reach maximum levels.

\section{DATA AND ANALYSIS}

The temperature- and pressure-corrected hourly data (counts of neutrons) of cosmic ray intensity from the Moscow neutron monitor have been used, where the long-term change was removed from the data by the method of trend correction. The days of Forbush decreases have also been removed to avoid their influence on cosmic ray variation. The IMF and solar wind plasma data have been taken from the interplanetary medium data books (see, e.g. [13-17]).

\section{RESULTS AND DISCUSSION}

Figure 1 (a-e) shows the plots of cosmic ray intensity (neutron monitor count rates of the Moscow NM, interplanetary magnetic field (B), disturbance storm time index $\left(\mathrm{D}_{\mathrm{st}}\right)$, solar wind velocity $(\mathrm{V})$, the product $(\mathrm{V} \times \mathrm{B})$, and the cosmic ray intensity normalized in a suitable manner so that they are juxtaposed to represent the continuous temporal variations of cosmic rays along with different parameters over four decades (1964-2004). 

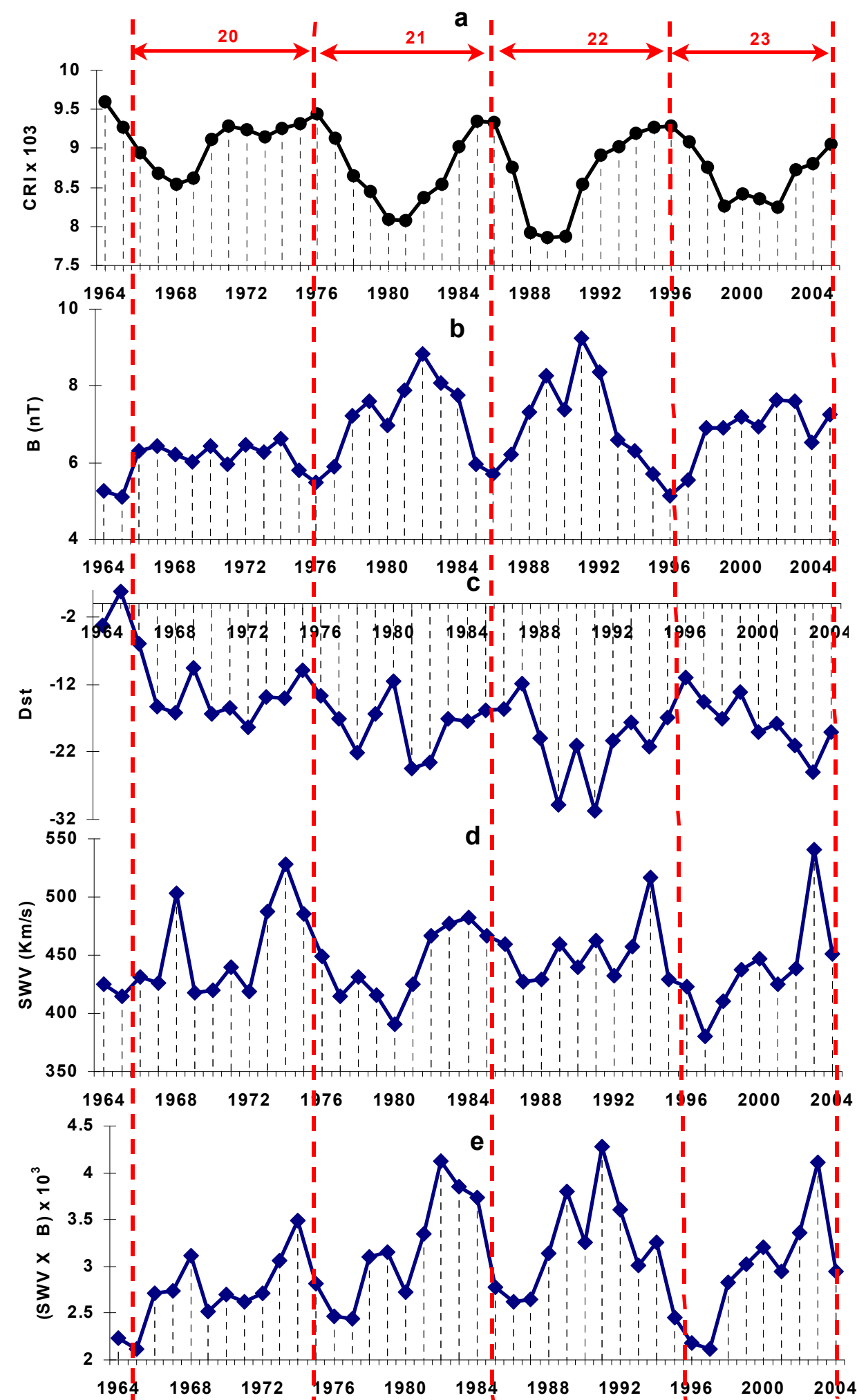

Fig. 1. Annual variation of cosmic rays with interplanetary magnetic field (B), disturbance storm time index $\left(D_{\text {st }}\right)$, solar wind velocity and the product $(\mathrm{V} \times \mathrm{B})$ during solar cycles 20-23. 
As depicted in Fig. 1, there is an inverse correlation between the cosmic ray intensity and the IMF strength (B). However, the maximum of cosmic ray intensity does not always occur at the IMF B minima. One can see from the plots that the increase in the $\mathrm{B}$ values and the product $(\mathrm{V} \times \mathrm{B})$ produce significant decrease in the cosmic ray intensity during the years 1982 and 1990-91. A significant negative correlation has been observed between IMF $\mathrm{B}$, product $(\mathrm{V} \times \mathrm{B})$ and the cosmic ray intensity during solar cycles 21 and 22 , whereas the disturbance time index and solar wind velocity seem to be positively correlated with the cosmic ray intensity, with some deviations during these cycles.

Further, one can see a linear positive correlation between the product $(\mathrm{V} \times \mathrm{B})$ and the interplanetary magnetic field. However, the maximum of IMF strength does not always occur at the $(\mathrm{V} \times \mathrm{B})$ maximum. To identify a possible correlation between these parameters, we have also calculated the correlation coefficient between these data strings for different solar cycles (20-23).

We have observed that the solar wind velocity has a good positive correlation $(0.45)$ during solar cycle 21 , whereas it has a weak correlation $(0.06,0.15$, -0.21 ) during cycles 20,22 and 23 with cosmic ray intensity. The cosmic ray intensity shows a good positive correlation $(0.39,0.57)$ with $\mathrm{D}_{\text {st }}$ index during solar cycles 21 and 22 , and a weak correlation $(0.10,0.12)$ for cycles 20 and 23 .

The IMF strength shows a weak negative correlation $(-0.35)$ with cosmic rays for solar cycle 20 , and a good anti-correlation for solar cycles $21-23(-0.76$, $-0.69)$ with the cosmic ray intensity.

Thus, from the above findings one may conclude that for four different solar cycles the cosmic ray intensity anti-correlates with the product of solar wind velocity by interplanetary magnetic field $(\mathrm{V} \times \mathrm{B})$ and the interplanetary magnetic field strength (B), with some deviations. However, the IMF B is found to linearly correlate with the product $(\mathrm{V} \times \mathrm{B})$ for four different solar cycles.

Barbara Popielawska [18] used the neutron monitor data from two pairs of cosmic ray stations, Kiel/Tsumeb and Climax/Huancayo, to study the rigidity dependence of solar modulation during the solar activity cycle 22 . She noticed that a long-term decrease in the cosmic ray intensity during the ascending phase of cycle 22 is characterized by the same rigidity dependence as for the long-term recovery during the descending phase of cycle 21.

Özgüç and Ataç [19] studied the hysteresis effect between the solar flare index and the cosmic ray intensity for the period from January 1, 1965 to December 31, 2001 on a daily basis. They show that a smoothed time series of flare index and the daily average of Calgary NM Galactic Cosmic Ray intensity values exhibit significant solar-cycle-dependent differences in their relative variations during the studied period, and the shapes of these differences vary from cycle to cycle.

Van Allen [20] showed that the annual averages of sunspot numbers vs. climax cosmic-ray intensity produce different patterns in even- and odd-numbered solar cycles (broad ovals in cycles 19 and 21, narrow ovals - straight lines to first order - in cycles 20 and 22). Van Allen did not consider the tilt angle in his analysis. In an earlier study, Nagashima and Morishita [21] applied the same technique as Van Allen using the ionization chamber data from Huancayo. Those authors found that the even-odd pattern in the relationship between sunspots and 
cosmic rays is also present (although not as clear) in the data from cycles 17 (peak sunspot number in 1937) and 18 (1947).

The cosmic-ray intensity curve also appears to follow a 22-year solar cycle with alternate maxima being flat-topped and peaked [22], as predicted by the models of cosmic-ray modulation based on the observed reversal of the Sun's magnetic field polarity every 11 years and curvature and gradient drifts in the largescale magnetic field of the heliosphere $[23,24]$. During the course of a recent study into the causes of the 11-year modulation cycle [25], it was noted that the cosmicray curve for solar cycle 21 ( 1980 peak) lagged the sunspot curve, while for cycle 22 ( $\sim 1990$ peak) the cosmic ray and sunspot variations were more closely synchronized.

\section{CONCLUSIONS}

From the present investigations the following conclusions could be drawn:

- Significant negative correlations have been observed between the interplanetary magnetic field strength $(\mathrm{B})$, the product $(\mathrm{V} \times \mathrm{B})$ and the cosmic ray intensity during solar cycles 21 and 22 .

- The solar wind velocity has a good positive correlation with the cosmic ray intensity during solar cycle 21 , whereas it shows a weak correlation during cycles 20,22 and 23.

- The interplanetary magnetic field shows a weak negative correlation with cosmic rays for solar cycle 20 , and a good anti-correlation for the solar cycles 21-23 with the cosmic ray intensity.

- The cosmic ray intensity shows a good positive correlation with disturbance time index during solar cycles 21 and 22, and a weak correlation for cycles 20 and 23.

\section{ACKNOWLEDGEMENTS}

The authors are indebted to various experimental groups, in particular, Prof. Margret D. Wilson, Prof. K. Nagashima, Miss Aoi Inoue and Prof. J.H. King for providing the data. The authors are also very much thankful to the anonymous referees for their useful comments/suggestions. We would also like to thank to Dr. A. K. Mandal, Director, Tropical Forest Research Institute, Jabalpur for providing the research facilities in the department in a very liberal manner.

\section{REFERENCES}

1. Forbush, S. E. (1954). J. Geophys. Res. 59, 525.

2. Ahluwalia, H. S. \& Wilson M. D. (1996). J. Geophys. Res. 101, 4879.

3. Cliver, E. W. \& Ling, A. G. (2001). Astrophys. J. Lett., 551, L189.

4. Berezhko, E. G., Brevnova, I. A., \& Starodubtsev, S. A. (1993). Astronomy Letters, 19 (4), 304.

5. Starodubtsev, S. A. (1999). Astronomy Letters, 25 (8), 540.

6. Starodubtsev, S. A. \&. Usoskin, I. G (2003). Astronomy Letters, $29,594$.

7. Perko, J. S., \& Burlaga, L. F. (1992). J. Geophys Res., 97, 4305.

8. Burlaga, L. F., \& Ness, N. F. (1998). J. Geophys. Res., 103, 29719. 
9. Belov, V., Guschina, R.T \&. Yanke, V. G (1999). Proc. $26^{\text {th }}$ Int. Cosmic Ray Conf., (7), 175.

10. Ahluwalia, H. S. (2000). Geophys. Res. Lett., 27, 1602.

11. Kota, J. \&. Jokipii, R. (1983). Astrophys. J., 265, 573.

12. Potgieter, M. S. \& Moraal, H. (1985). Astrophys. J., 294, 425.

13. King, J. (1983). Interplanetary Medium Data Book-Supplement 2, NSSD/WDC-A, Goddard Space Flight Center, Greenbelt, MA.

14. King, J. (1986a). Interplanetary Medium Data Book-Supplement 3, NSSD/WDC-A, Goddard Space Flight Center, Greenbelt, MA.

15. King, J. (1986b). Interplanetary Medium Data Book-Supplement 3A, NSSD/WDC-A, Goddard Space Flight Center, Greenbelt, MA.

16. King, J. (1989). Interplanetary Medium Data Book-Supplement 4, NSSD/WDC-A, Goddard Space Flight Center, Greenbelt, MA.

17. King, J. \& Papitashvili, N. E. (1994). Interplanetary Medium Data Book, NSSCD/WDC-A-R@S94-08, Goddard Space Flight Center, Greenbelt, Maryland.

18. Popielawska, B. (1995). J. Geophys. Res., 100 (A4), 5883.

19. Özgüç, \& Ataç, T. (2003). New Astronomy, 8 (8), 7453.

20. Van Allen, J. A. (2000). Geophys. Res. Lett., 27, 2453.

21. Nagashima, K. \& Morishita, I. (1980). Planet. Space Sci., 28, 195.

22. Smith, E. J. J. (1990) Geophys. Res., 95, 18, 731.

23. Jokipii, J. R., Thomas, B. T., Levy, E. H. \& Hubbard, W. B. (1977). ApJ, 213, 861.

24. Jokipii, J. R. \& Thomas, B. T. (1981). ApJ, 243, 1115.

25. Cliver, E. W. \& Ling, A. G. (2001). ApJ, 551, L189.

\title{
KOSMISKO STARU INTENSITĀTES IZMAIN̦AS SAULES CIKLOS ATKARĪBĀ NO STARPPLANETTU UN SAULES VĒJA PLAZMU PARAMETRIEM
}

\author{
Rajesh K. Mishra, Rekha Agarwal, Sharad Tiwari
}

Kopsavilkums

Galaktikas kosmiskie stari modulēti, tiem izplatoties heliosfērā pie lieliem starpplanētu struktūru efektiem. Kosmisko staru intensitātes izmaiņu dati, kuri iegūti neitronu monitoringa stacijās, tiek salīdzināti ar geomagnētisko perturbanču datiem, Saules vēja ātrumu (V), starpplanētu magnētiskais lauku (B) un to reizinājumu $(\mathrm{V} \times \mathrm{B})$ tuvu Zemei, laika posmā no 1964. gada līdz 2004. gadam, tie tika doti, lai noteiktu iespējamo korelāciju starp tiem.

Mēs izmantojām pa stundām vidējoto kosmisko staru skaitu, kas tika novēroti neitronu monitoringa stacijā Maskavā. Redzams, ka būtiska negatīva korelācija tika novērota starp starpplanētu magnētiskā lauka (B) un Saules vēja ātruma (V) reizinājumu $(\mathrm{V} \times \mathrm{B})$ un kosmisko staru intensitāti Saules 21 un 22 ciklu laikā. Saules vēja ātrumam un kosmisko staru intensitātei ir pozitīva korelācija Saules 21 cikla laikā, bet vāja korelācija - 20, 22, 23 ciklu laikā.

Starpplanētu magnētiskajam laukam ir vāja korelācija ar kosmisko staru intensitāti Saules 20 cikla laikā, bet laba antikorelācija- Saules 21-23 ciklos, kas savukārt parāda labu pozitīvu korelāciju ar perturbances laika indeksu ( $\left.\mathrm{D}_{\mathrm{st}}\right)$ Saules 21 un 22 ciklos un vāju korelāciju 20 un 23 ciklos.

18.09.2007. 